\title{
Tendencias y patrones de la migración de retorno en México
}

\author{
Trends and patterns of return migration in Mexico
}

Alejandro I. Canales*

ISSN IMPRESO 1870-7599 | ISSN RED CÓMPUTO 2448-7783 | 123-155

Sofía Meza*

Resumen. En este documento ofrecemos un análisis de los perfiles, volúmenes y patrones de la migración de retorno en México, comparándolos en tres momentos diferentes: a) antes de la crisis económica y durante el gran auge de la emigración a los Estados Unidos; b) durante la crisis económica y momentos de mayor endurecimiento de la política antiinmigrante, y que implicó un virtual desplome temporal de la migración mexicana; c) la etapa posterior a la crisis económica, y en un contexto de moderado reimpulso de la emigración de mexicanos a los Estados Unidos. Nos interesa discutir si el crecimiento del retorno a fines de la década pasada fue sólo un fenómeno coyuntural producto de las peculiares circunstancias que lo provocaron, o por el contrario, implicó cambios en los perfiles y patrones del retorno, que aunque se redujeron en volumen, persisten actualmente conformando un fenómeno emergente cuyas implicancias y consecuencias aún no están claramente definidas.

Palabras clave: migración de retorno, crisis económica, hogares, regiones, México.

Abstract. In this paper we offer an analysis of the nature, volume and patterns of return migration in Mexico, comparing them across three distinct moments: $i$ ) before the economic crisis and during the great boom in emigration to the United States; ii) during the economic crisis and periods of increased strengthening of anti-immigrant policies, and which resulted in a temporary collapse of Mexican migration; and iii) the later stage of economic crisis, and within a context of a moderate resumption of Mexican emigration to the United States. We discuss whether the growth of return migration at the end of the last decade was only a circumstantial phenomenon, the product of particular circumstances, or on the contrary, that it implied a change in the nature and pattern of return migration, that although the volume was reduced, its continuance represents an emerging phenomenon whose implications and consequences are still not clearly defined.

Keywords: return migration, economic crisis, households, regions, Mexico. 



\section{Introducción}

Hasta 2008 el análisis y la problematización de la migración de retorno en México no había ocupado un lugar preponderante en el debate sobre las migraciones, es hasta la crisis económica de ese año que derivó en el endurecimiento de las políticas antiinmigrantes y el aumento de deportaciones implementadas desde mediados de la década de 2000, que el retorno comienza a ser un tema trascendental.

Desde los primeros años de la crisis se observó un intenso flujo de retorno que superó con creces al registrado en años anteriores. Ello, aunado a la reducción del flujo de salida de migrantes desde México, llevó a que algunos autores hablaran de una fase de saldo migratorio nulo para ese periodo (Galindo, 2015; Passel, Cohn y González-Barrera, 2012); otros fueron más allá y plantearon la hipótesis de un posible colapso de la migración de mexicanos a Estados Unidos (Durand y Arias, 2014).

Sin embargo, es evidente que las cifras no son tan concluyentes al respecto. En un primer momento se registró incluso un saldo neto negativo, que condujo a que el volumen de mexicanos residentes en Estados Unidos disminuyera de 12 millones en 2008 a 11.6 millones en 2011, nivel que se mantuvo hasta mediados de 2014. A finales de ese año inicia una nueva fase que reimpulsa la emigración mexicana, lo que permitió que el volumen de mexicanos residentes en Estados Unidos incrementara a más de 12.2 millones a inicios de 2018; un volumen que superó al que había hasta antes de esa crisis. ${ }^{1}$

Un componente central en esta tendencia de la migración es el flujo de migrantes de retorno, el cual si bien una vez pasados los momentos más álgidos de la crisis económica y de las deportaciones se habría reducido sustancialmente, aún se mantiene en niveles superiores a los prevalecientes en décadas anteriores (Canales y Meza, 2016). En ese sentido es posible afirmar que aunque la migración de retorno se originó en una situación de tipo coyuntural, donde se conjuntaron distintas condiciones (crisis económica junto a una política de restricciones y deportaciones), adquiere mayor relevancia en la dinámica y estructura del sistema migratorio México-Estados Unidos, cuyos impactos y consecuencias son de diverso tipo (Gandini, Lozano y Gaspar, 2015).

\footnotetext{
${ }^{1}$ Estimaciones propias con base en datos de Current Population Survey, módulo mensual de enero de 2008 a febrero de 2018. Cifras anualizadas con fundamento en promedios móviles de los datos mensuales para cada año.
} 
Frente a ello, interesa analizar perfiles, volúmenes y patrones durante el boom del retorno y compararlos con los prevalecientes antes y después de la crisis económica. El objetivo es investigar si el crecimiento del retorno fue sólo un fenómeno coyuntural producto de las peculiares circunstancias que lo provocaron, o por el contrario, implicó cambios en los perfiles y patrones del retorno, que a pesar de que disminuyeron en volumen, abarcan un fenómeno emergente cuyas implicaciones y consecuencias todavía no están definidas de forma clara.

Sobre el flujo de retorno se ha desarrollado una amplia literatura. Destacan los textos de Gandini, Lozano y Gaspar (2014 y 2015), quienes han hecho aportes significativos a la caracterización sociodemográfica de tales flujos, así como su distribución territorial y rural-urbana. ${ }^{2}$ Los estudios de retorno en México suelen centrarse en el análisis de los datos del Censo de Población de 2010, que ofrece una gran potencialidad para entender el fenómeno del retorno, pero por razones obvias no recoge la dinámica del fenómeno a partir de entonces.

En nuestro caso, es prioritario examinar el retorno que incorpore la información estadística y demográfica más reciente en México; eso permitirá identificar nuevas fases y coyunturas del proceso de retorno, además de otras dimensiones del flujo migratorio. Es posible establecer tres grandes fases o momentos del retorno en la actual coyuntura histórica de las migraciones México-Estados Unidos: a) antes de la crisis económica, que coincide con el auge de la emigración a Estados Unidos; $b$ ) periodo de la crisis económica y de mayor endurecimiento de la política antiinmigrante; c) etapa posterior a la crisis económica, en un contexto de reimpulso de la emigración de mexicanos a Estados Unidos.

El estudio incluye el análisis y entendimiento del retorno en México comparando su dinámica, composición y perfiles en esos tres aspectos de su tendencia en las últimas dos décadas. En la primera sección se revisan las causas y determinantes del retorno, se describen brevemente sus niveles y tendencias, hecho que permite identificar tales etapas. En la segunda, se expone el perfil sociodemográfico de los migrantes de retorno, se consideran los periodos señalados. En la tercera, se reflexiona acerca de los hogares, se identifican patrones de retorno individual y colectivo o familiar. En la cuarta, se ponderan los patrones de la configuración territorial del retorno con base en las regiones migratorias y entidades federativas.

${ }^{2}$ Para una revisión exhaustiva de los estudios sobre migración de retorno en México véase Canales y Meza, 2018. 


\section{Retorno: causas y determinantes}

Si bien múltiples factores intervienen en el repentino auge del retorno de mexicanos, la presente investigación se centra en dos de ellos: los efectos de la crisis económica y las consecuencias de la política de restricciones y deportaciones.

\section{Retorno en el marco de la crisis económica}

La crisis económica financiera en Estados Unidos detonó la contracción de los mercados de trabajo en los sectores donde típicamente se concentran los migrantes mexicanos: construcción, manufactura, agricultura y servicios. ${ }^{3}$ Ramírez y Aguado (2013), apoyados en un modelo logístico, analizaron los factores determinantes de la migración laboral de retorno entre 2007-2009; encontraron que la falta o término de su trabajo, así como la falta de ingresos suficientes para permanecer en aquel país, fueron los factores que más incidieron en la propensión para regresar a México.

Además de resultar perjudicada con la disminución del empleo disponible, la migración mexicana tuvo que lidiar con la precarización del mismo. Al respecto, Canales (2014) indica que los migrantes son uno de los sectores más vulnerables y con menor poder de negociación social y política, por lo que era previsible que una de las consecuencias de la crisis económica fuera la virtual transferencia hacia ese grupo de gran parte de su costo. En el caso de los mexicanos el desempleo alcanzó en su peor momento 13.3 por ciento; por su parte, más de 20 por ciento se empleaba en condiciones de alta precariedad laboral, proporción que duplicaba la de otras minorías étnicas y demográficas, y triplicaba la de los trabajadores blancos no latinos.

La evolución de la crisis tomó varias formas, ello afectó el empleo de distintos tipos de migrantes de modo diferenciado. En una primera etapa, como crisis financiera, tuvo grandes impactos en los trabajadores migrantes altamente capacitados; ${ }^{4}$ en tanto que los de baja calificación laboral fueron afectados de

\footnotetext{
${ }^{3}$ Ramírez y Aguado (2013), con datos de la EMIF Norte, indican que entre 2007-2009 la mayoría de los migrantes de retorno reportó haber trabajado en Estados Unidos: 36.3 por ciento lo hizo en el sector de la construcción; 30.3 por ciento en el de servicios; y 22.3 por ciento en el agropecuario.

${ }^{4}$ Para analizar las características de la vulnerabilidad de la migración latinoamericana con altos niveles de escolaridad frente a la crisis, puede consultarse a Gandini y Lozano, 2015; mientras que para priorizar el caso mexicano véase Gandini y Lozano, 2012.
} 
manera directa por la disminución en la demanda de trabajadores en el sector de la construcción y la precarización del empleo en servicios no calificados. Lo anterior provocó que la crisis financiera derivara en una crisis de empleo para los inmigrantes de baja calificación, lo que agravó su situación de vulnerabilidad social y laboral, puesto que se redujeron sus opciones de empleo y empeoraron sus condiciones laborales, salarios y jornadas laborales (Castles y Miller, 2010).

\section{Retorno en el marco de la política antiinmigrante y de deportaciones}

A finales de los 1990 se gesta un cambio radical en la orientación de la política migratoria de Estados Unidos que se consolida a partir de los atentados del 11 de septiembre. La base ideológica es la doctrina de la seguridad interna que pone como prioridad la lucha contra el terrorismo, y relega a un segundo y tercer orden el enfoque de derechos humanos en la definición de la política migratoria (Alarcón, 2016). Con el objetivo de reforzar la seguridad en las fronteras se promueven políticas y programas antiinmigrantes como el de Comunidades Seguras, que implicaron la implementación de diversos mecanismos de control no sólo en las zonas fronterizas, sino también en los lugares de vivienda y trabajo de los migrantes en Estados Unidos (Canales y Meza, 2018).

Esta clase de políticas gubernamentales fortaleció actitudes de discriminación y xenofobia por parte de distintos sectores estadounidenses en contra de los inmigrantes latinos en particular. Massey, Pren y Durand (2009), al igual que Ramírez y Aguado (2013), insisten en cómo la promulgación de la denominada Ley Patriota (USA Patriot Act), junto a otras políticas discriminatorias elaboradas años antes a escala nacional y local, han contribuido a esa construcción social del migrante como potencial peligro criminal.

El resultado de esas reformas legales fue la expansión de la tipificación de los crímenes y delitos relacionados con la inmigración, así como el número de delitos y faltas estatales y federales que conducen a la eventual remoción de los inmigrantes. Junto a ello, restringen los criterios de los jueces de inmigración que pudieran llevar a una limitación o suspensión del proceso de remoción de inmigrantes. Por último, se amplían las categorías y tipificaciones de no ciudadanos sujetos a detención y posible remoción (Meissner et al., 2013).

Luego de los atentados terroristas del 11 de septiembre de 2001 se reformaron las leyes y actas que regulan tanto la situación de los migrantes indocumentados, como las atribuciones de los distintos agentes vinculados al control 
migratorio y de la población en general (Alarcón y Becerra, 2012). Lo anterior amplió la capacidad de vigilancia y control del gobierno con la finalidad de capturar posibles terroristas. Entre esas políticas, la Ley Patriota propició la implementación de radicales medidas de control social y político de la población; se incluyó la aplicación de redadas masivas en zonas fronterizas y al interior del país, que aunque fueron diseñadas para perseguir y atrapar terroristas, en la práctica remitieron sobre todo contra los migrantes latinos e indocumentados (Massey, Pren y Durand, 2009). ${ }^{5}$

Uno de los principales instrumentos en los que se basa la estrategia de endurecimiento de la política antiinmigrante es la nueva política de deportaciones, que además de criminalizar la inmigración indocumentada ha derivado en una masiva deportación de extranjeros, lo cual afecta de manera preferente a los inmigrantes mexicanos (Rivera, 2015). Según datos del Departamento de Seguridad Nacional de los Estados Unidos, las deportaciones de mexicanos prácticamente se habrían duplicado: de 1.3 millones en el periodo 1998-2006 a casi 2.5 millones en 2007-2015. En ese lapso se deportaron casi 270 mil mexicanos cada año, ello conformó uno de los principales componentes del retorno de mexicanos en la última década (Canales y Rojas, 2017).

\section{Niveles y tendencias del retorno en México: entre mitos y datos}

Uno de los puntos que propició el debate y análisis del retorno en el país fue el volumen que alcanzó en la segunda mitad de la década de 2000. La conjunción de una crisis económica y de empleos en Estados Unidos, por un lado, y el endurecimiento de la política migratoria y de deportaciones, por el otro, marcaron el contexto del incremento, inusual hasta ese entonces, de los volúmenes de migrantes mexicanos de retorno en México.

Los datos corroboran inicialmente dicha tesis y muestran que, en efecto, hay un crecimiento sustantivo del volumen de retornos a partir de la crisis económica de 2008. Sin embargo, las mismas fuentes ilustran una disminución

${ }^{5}$ Es importante reflexionar sobre el estigma del retorno debido a una deportación, como lo hace Masferrer (2014); o la repercusión cuando se retorna en un lugar diferente al de origen, así como las dificultades para reinsertarse en el país de origen bajo un contexto de criminalización de la deportación o repatriación, como lo plantean Lozano y Martínez (2015). 
del retorno en años recientes, en especial desde la recuperación del empleo en Estados Unidos, y la reducción del volumen de deportaciones y remociones implementadas por las autoridades norteamericanas.

A partir de 1990 los censos y conteos de población mexicanos, así como las encuestas demográficas, preguntan por el lugar de residencia de los individuos cinco años antes del levantamiento censal o la encuesta. Eso permite medir la migración de retorno reciente, lo que da una idea panorámica de la tendencia del retorno en las últimas tres décadas. ${ }^{6}$ Como se observa en el siguiente gráfico, hasta el quinquenio 2001-2006 el retorno se mantenía en volúmenes muy reducidos; en el mejor de los casos representaba un flujo inferior a 60 mil retornos anuales, siendo su punto más bajo en dicho periodo con menos de menos de 40 mil retornos anuales. No obstante, en la segunda mitad de los 2000 el retorno se incrementó significativamente: pasó de 121 mil migrantes anuales de 20042009 a más de 165 mil en 2005-2010. Desde entonces el flujo empezó a descender: tuvo un volumen de 111 mil retornos anuales en 2009-2014 y de 2010-2015 fue de $88.6 \mathrm{mil}$. Si bien este último flujo representa la mitad de lo experimentado en el quinquenio anterior (2005-2010), casi duplica el volumen histórico hasta antes de 2005.

La tendencia indica que México experimentó un boom del retorno en el lapso de la crisis económica, el endurecimiento de las políticas antiinmigrantes y las deportaciones masivas. Asimismo, señala que cuando la economía y el empleo en Estados Unidos se recupera, el retorno se reduce de manera significativa aunque se mantiene por encima de los niveles históricos.

\footnotetext{
${ }^{6}$ En la presente investigación la migración de retorno comprende a aquellas personas originarias de México que en algún momento residieron en Estados Unidos, y que regresaron a vivir a su país. Los censos de población y las encuestas demográficas mexicanas especifican el tiempo y los momentos del retorno, de tal modo que el migrante de retorno sería aquella persona nacida en México que hasta cinco años antes del levantamiento censal o la encuesta radicaba en Estados Unidos, y volvió a México durante los últimos cinco años. En otras encuestas la referencia temporal de la residencia en Estados Unidos y del momento del regreso a México varían, pero se mantiene la definición original de mexicanos que emigraron a aquel país y regresaron a su lugar de nacimiento. Esa forma de medir la migración de retorno, además de su sencillez, posee la virtud de que puede hacerse un análisis comparativo en diversos momentos, pues la misma metodología ha sido usada en encuestas demográficas nacionales así como en los censos y conteos de población. No obstante, tiene también limitaciones relevantes: restringe la medición del retorno a la población mayor de cinco años, por lo que no es posible examinar la migración de menores que acompañan a sus padres en el retorno.
} 


\section{GRÁFICA 1}

Tendencia histórica de la migración de retorno a México

(flujos quinquenales, miles de personas)

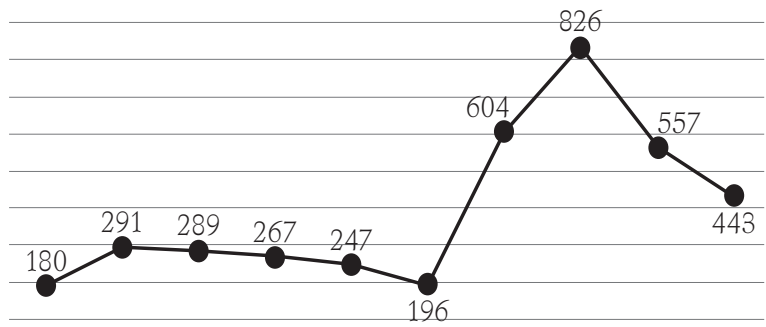

\begin{tabular}{|c|c|c|c|c|c|c|c|c|c|}
\hline  &  & 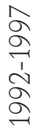 & 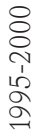 & 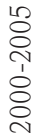 &  & 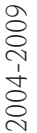 & 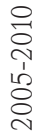 & 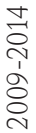 & 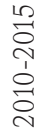 \\
\hline
\end{tabular}

Fuente: elaboración propia con datos del Censo de Población (1990, 2000, 2010), Conteo de Población $(1995,2005)$, Encuesta Nacional de la Dinámica Demográfica (ENADID) $(1992,1997,2009,2014)$ y Encuesta Intercensal (2015).

Los datos de la Encuesta Nacional de Ocupación y Empleo (ENOE) ofrecen un análisis más detallado de esa tendencia, pues permiten identificar trimestre a trimestre las distintas fases del retorno, además de los puntos de inflexión en sus tendencias recientes. ' En concreto, desde 2005 a la fecha (cuarto trimestre de 2017), es posible reconocer tres fases en la tendencia del retorno en México: a) El retorno adquiere su máxima expresión en la segunda mitad de los 2000. Los datos de la ENOE corroboran ese hecho y registran que entre 2005 y 2009 la migración de retorno alcanza un volumen de 337 mil migrantes anuales en promedio. b) Entre el primer trimestre de 2010 y el primer trimestre de 2014 el retorno experimenta una fase de reducción sostenida, pasa de 300 mil a sólo 100 mil migrantes de retorno cada año. c) Desde el primer trimestre de 2014, y hasta la actualidad, el retorno ha permanecido estable: alrededor de 100 mil migrantes al año, cifra menor al tercio de la cantidad obtenida en los momentos de mayor retorno, pero significativa en un contexto de reducción de los flujos de emigración a Estados Unidos (Canales y Meza, 2016).

${ }^{7}$ Las cifras que aporta la ENOE no necesariamente concuerdan con las estimadas a partir de los censos y encuestas demográficas pues difieren en el concepto y la dimensión temporal del retorno que cada instrumento mide así como en la metodología de recolección de la información. 


\section{GRÁFICA 2}

Migrantes de retorno. Flujo anualizado

con base en promedio de trimestre móvil

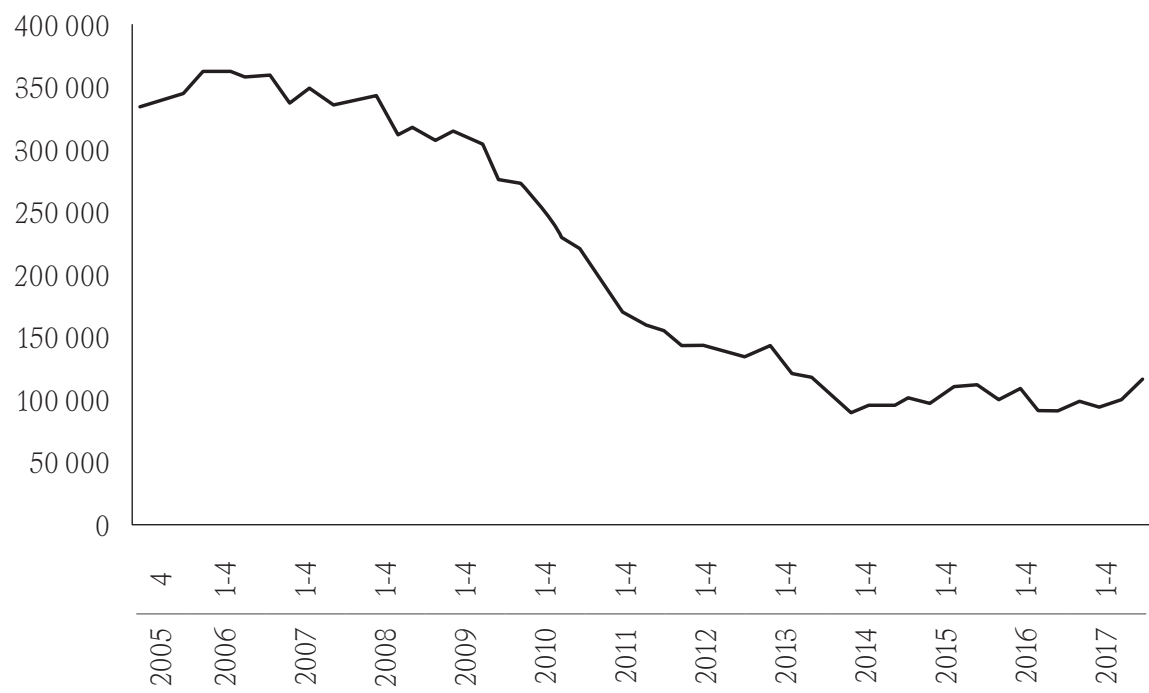

Más allá de las desemejanzas en los volúmenes que se estiman con distintas fuentes estadísticas, lo relevante es constatar un mismo patrón y tendencia del retorno; ello se refleja tanto con datos de censos y encuestas demográficas como con la medición continua trimestre a trimestre que proporciona la ENOE, y que puede definirse como un proceso de auge y contracción. Con base en tales tendencias, es primordial analizar si esas múltiples fases del retorno implican también patrones y perfiles diferentes en cada momento, o si por el contrario, sólo se reflejan en sus montos y volúmenes absolutos.

\section{Características sociodemográficas del retorno reciente}

El retorno es un fenómeno esencialmente masculino, según lo evidencia su constancia a lo largo del tiempo. Antes, durante y después de la crisis económica la participación masculina en la migración de retorno superó en relación de 
2 a 1 a la femenina; lo notable es que dicha preeminencia se acentuó en ese escenario. En el quinquenio 1995-2000 la correspondencia era de 187 hombres por cada 100 mujeres, la cual se incrementó a 257 en 2005-2010, en plena crisis económica, y se redujo a 211 en el periodo de poscrisis entre 2010 y 2015.

Estas disimilitudes son más patentes al comparar las tasas de retorno por sexo, es decir, la proporción que representan los migrantes de retorno respecto a la población mexicana residente en Estados Unidos al inicio de cada quinquenio considerado. ${ }^{8}$ Los datos indican que los hombres muestran desde siempre una mayor propensión a regresar que las mujeres. Antes de la crisis, 4.5 por ciento de los hombres volvía a México, contra sólo 3.0 por ciento de las mujeres. Esa diferencia se acentuó durante la crisis, cuando la tasa de retorno de los hombres subió a 9.7 por ciento: prácticamente 1 de cada 10 migrantes hombres regresó en el quinquenio 2005-2010, mientras que la proporción de las mujeres fue de 4.7 por ciento. Finalmente, en el periodo de poscrisis las tasas llegaron a sus niveles originales antes de la crisis y se mantuvo la mayor propensión de los hombres a reingresar al país.

\section{CUADRO 1}

Características sociodemográficas de la migración de retorno proveniente de Estados Unidos

\begin{tabular}{|c|c|c|c|c|c|c|c|c|c|}
\hline & \multicolumn{3}{|c|}{$\begin{array}{l}\text { Volumen } \\
\text { absoluto }\end{array}$} & \multicolumn{3}{|c|}{$\begin{array}{l}\text { Distribución } \\
\text { relativa (\%) }\end{array}$} & \multicolumn{3}{|c|}{$\begin{array}{c}\text { Tasas } \\
\text { de retorno (\%) }\end{array}$} \\
\hline & $\begin{array}{l}1995- \\
2000\end{array}$ & $\begin{array}{c}2005- \\
2010\end{array}$ & $\begin{array}{c}2010- \\
2015\end{array}$ & $\begin{array}{l}1995- \\
2000\end{array}$ & $\begin{array}{l}2005- \\
2010\end{array}$ & $\begin{array}{l}2010- \\
2015\end{array}$ & $\begin{array}{l}1995- \\
2000\end{array}$ & $\begin{array}{l}2005- \\
2010\end{array}$ & $\begin{array}{l}2010- \\
2015\end{array}$ \\
\hline Sexo & 267150 & 825609 & 442503 & 100 & 100 & 100 & 3.8 & 7.5 & 3.7 \\
\hline Hombres & 173929 & 594553 & 300139 & 65 & 72 & 68 & 4.5 & 9.7 & 4.6 \\
\hline Mujeres & 93221 & 231056 & 142364 & 35 & 28 & 32 & 3.0 & 4.7 & 2.7 \\
\hline $\begin{array}{l}\text { Índice } \\
\text { masculinidad }\end{array}$ & 187 & 257 & 211 & & & & & & \\
\hline
\end{tabular}

${ }^{8}$ Tales tasas se calculan como el cociente entre los migrantes de retorno en determinado periodo quinquenal y la población mexicana residente en Estados Unidos al inicio de ese quinquenio, y así para cada subpoblación que se considere. Por ejemplo, la tasa de hombres para 2005-2010 es la relación entre los migrantes de retorno masculinos en ese quinquenio registrados por el Censo de 2010, y el total de migrantes mexicanos hombres asentados en Estados Unidos en 2005 consignados por Current Population Survey del Buró del Censo de Estados Unidos. Se toma como referencia la población establecida en ese país, por estar expuesta a experimentar un evento de retorno. 


\begin{tabular}{|c|c|c|c|c|c|c|c|c|c|}
\hline & & $\begin{array}{l}\text { Volumen } \\
\text { absoluto }\end{array}$ & & & $\begin{array}{l}\text { stribuc } \\
\text { atival }\end{array}$ & & & $\begin{array}{l}\text { Tasas } \\
\text { etorno }\end{array}$ & \\
\hline & $\begin{array}{l}1995- \\
2000\end{array}$ & $\begin{array}{c}2005- \\
2010\end{array}$ & $\begin{array}{l}2010- \\
2015\end{array}$ & $\begin{array}{l}1995- \\
2000\end{array}$ & $\begin{array}{l}2005- \\
2010\end{array}$ & $\begin{array}{r}2010- \\
2015\end{array}$ & $\begin{array}{l}1995- \\
2000\end{array}$ & $\begin{array}{l}2005- \\
2010\end{array}$ & $\begin{array}{r}2010- \\
2015\end{array}$ \\
\hline Edad & 266416 & 741050 & 399654 & 100 & 100 & 100 & 3.8 & 7.5 & 3.7 \\
\hline 5-19 & 40979 & 79631 & 41623 & 15 & 10 & 9 & 5.7 & 8.4 & 6.4 \\
\hline $20-39$ & 168509 & 523619 & 239603 & 63 & 63 & 54 & 4.8 & 10.4 & 5.4 \\
\hline $40-59$ & 43671 & 187863 & 134427 & 16 & 23 & 30 & 2.1 & 4.8 & 2.7 \\
\hline $60+$ & 13235 & 34045 & 26617 & 5 & 4 & 6 & 2.0 & 2.9 & 1.5 \\
\hline $\begin{array}{l}\text { Edad } \\
\text { promedio }\end{array}$ & 31.4 & 33.7 & 36.3 & & & & & & \\
\hline $\begin{array}{l}\text { Edad } \\
\text { mediana }\end{array}$ & 30.0 & 32.0 & 35.0 & & & & & & \\
\hline Escolaridad & 220416 & 741050 & 399654 & 100 & 100 & 100 & 3.8 & 7.5 & 3.7 \\
\hline $\begin{array}{l}\text { Primaria } \\
\text { completa }\end{array}$ & 101327 & 285620 & 134301 & 46 & 39 & 34 & 4.1 & 9.3 & 4.7 \\
\hline $\begin{array}{l}\text { Preparatoria } \\
\text { incompleta }\end{array}$ & 74369 & 298265 & 159997 & 34 & 40 & 40 & 4.0 & 9.2 & 4.5 \\
\hline $\begin{array}{r}\text { Preparatoria } \\
\text { completa }\end{array}$ & 25624 & 97172 & 64763 & 12 & 13 & 16 & 2.4 & 4.1 & 2.3 \\
\hline $\begin{array}{r}\text { Licenciatura } \\
\text { o más }\end{array}$ & 19096 & 59993 & 40593 & 9 & 8 & 10 & 2.4 & 4.3 & 2.1 \\
\hline
\end{tabular}

La tasa de retorno corresponde a la proporción que representan los migrantes de retorno de cada quinquenio respecto a la población mexicana residente en Estados Unidos al inicio del quinquenio correspondiente.

Fuente: elaboración propia con datos del Censo de Población (2000, 2010), Encuesta Intercensal (2015) y Current Population Survey (2000, 2010, 2015).

En cuanto a la composición por edad del retorno, la mayor proporción la ocupa la población en edades jóvenes, plenamente activas. Sin embargo, se observa una situación de envejecimiento del retorno, lo cual se explica por el envejecimiento propio y natural de toda población migrante. En concreto, los migrantes de retorno con más de 40 años pasaron de 21 por ciento en 1995-2000 a 27 por ciento en 2005-2010 y a 36 por ciento en la actualidad. Por el contrario, los infantes y adultos jóvenes redujeron su participación de 15 y 63 por ciento en el primer quinquenio, respectivamente, a 9 y 54 por ciento en el quinquenio de la poscrisis. Este cambio es un fenómeno natural que responde, en cierto modo, al envejecimiento de la población mexicana residente en Estados Unidos.

No obstante, al analizar las tasas de retorno se percibe que el comportamiento frente a éste es marcadamente diferenciado por edad, pero en sentido 
inverso al ya señalado; la propensión a retornar tiende a disminuir con la edad, y ser mayor entre jóvenes y niños. Asimismo, la crisis manifiesta un impacto diferenciado por edades, lo que profundiza esa distinción en el retorno. Antes de la crisis la tasa de retorno era de 5.7 por ciento en los menores de 20 años y de 4.8 por ciento en los migrantes de 20 a 39 años. Se advierte que la tendencia está por encima de la prevaleciente entre migrantes de 40 a 59 años y mayores de 60.

Si bien la crisis habría afectado a todos, tuvo más incidencia en los migrantes jóvenes. La tasa de retorno de personas entre 20 y 39 años incrementó a 10.4 por ciento, cifra que superó a la de menores de 20 años y aún más a la de mayores de 40 años. Un dato sobresaliente es que la crisis no parece haber tenido gran impacto en adultos mayores de 60 años, pues fueron el sector con menos incremento en tasa de retorno.

En el periodo de la poscrisis, entre 2010 y 2015, las propensiones de retorno volvieron a sus niveles originales antes de la crisis, y reprodujeron el modelo general donde la tasa de retorno se reduce sistemáticamente con la edad. Esto plantea una situación peculiar. A pesar de que el retorno en la poscrisis muestra un mayor envejecimiento (participación de adultos y adultos mayores), sus tasas son casi las mismas que en el quinquenio antes de la crisis. Ello indica que el cambio en la composición relativa del retorno en la poscrisis obedece más a un proceso estructural de envejecimiento de la población migrante, que a una variación en el comportamiento respecto al retorno de cada estrato etario.

La migración de retorno evidencia también una selectividad por nivel de escolaridad; es mayor tanto en volumen como en tasas en los migrantes con menor escolaridad, y desciende de forma significativa entre los de más escolaridad. Así, la mayor proclividad se encuentra en los migrantes de baja y muy baja escolaridad. Aun cuando su participación tiende a reducirse, todavía en 2010-2015 40 por ciento de los retornados no había completado el nivel de preparatoria, mientras que otro tercio apenas había finalizado los estudios de primaria. Asimismo, aunque ha incrementado la proporción de retornados con niveles medios y altos de escolaridad, todavía se mantiene en niveles mínimos.

Aunado a lo anterior, la crisis económica agudizó la problemática pues la brecha entre las tasas de retorno se incrementó. Si antes y después de la crisis la tasa de retorno en los migrantes de baja escolaridad alcanzó alrededor de 4 por ciento, se elevó a 9 por ciento en 2005-2010. En contraposición, la tasa de retorno entre los migrantes de mayor escolaridad (preparatoria completa o más) que ya era baja antes de la crisis, apenas tuvo 4 por ciento durante ésta; luego 
retomó en 2010-2015 los niveles precedentes, que no superaban 2.5 por ciento. En ese sentido, la crisis económica afectó a los migrantes en diferente medida e intensidad: el impacto en la propensión de retorno fue superior entre quienes sólo poseían estudios de primaria completa o preparatoria incompleta.

\section{Hogares y retorno}

Una manera alternativa de dimensionar el retorno es examinar su presencia en los hogares. Según los datos, el volumen de hogares con migrantes de retorno sigue el mismo patrón que el retorno examinado a nivel individual. Antes de la crisis en el quinquenio 1995-2000 se registraban 191.5 mil hogares con migrantes de retorno, lo que representaba sólo 0.8 por ciento de los hogares en México. Diez años después, en 2005-2010, el volumen se triplicó, pues se documentaron 628.5 mil hogares con migrantes de retorno, cantidad equivalente a 2.2 por ciento del total de hogares en este país. Tal cifra aporta información relevante si se considera que los hogares no se distribuyen de modo uniforme, sino que suelen concentrarse en determinados espacios regionales y tipos de localidades. Cinco años después, en 2010-2015, el volumen se redujo a 363.3 mil, suma que a pesar de ser superior a la persistente antes de la crisis económica, constituye sólo 1.1 por ciento del total de dichos hogares, es decir, la mitad de la que predominó en el quinquenio anterior.

\section{GRÁFICA 3}

Hogares con migrantes de retorno en México.

Volumen total y tasa respecto al total de hogares

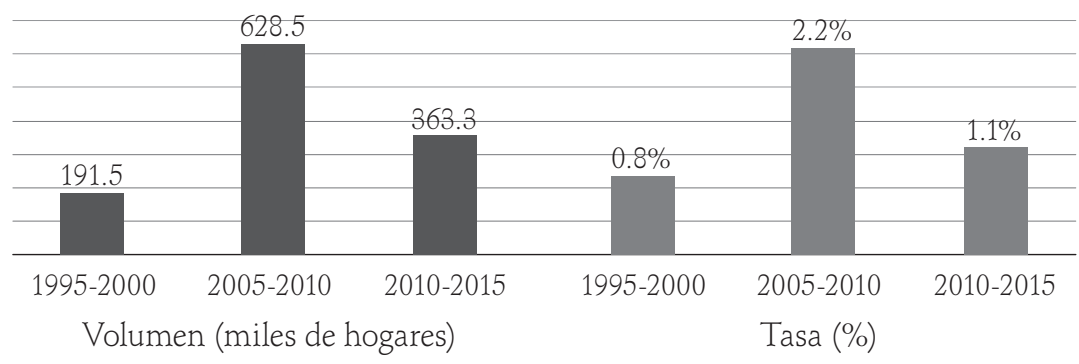

Fuente: elaboración propia con datos del Censo de Población (2000, 2010) y Encuesta Intercensal (2015). 
Gandini, Lozano y Gaspar (2014) plantean un análisis sociodemográfico de los hogares y el retorno, los clasifican de acuerdo con su tipo de actividad migratoria; toman en cuenta cuatro categorías: presencia de emigrantes internacionales, presencia de migrantes circulares, recepción de remesas y presencia de migrantes de retorno. Tal enfoque permite subdividir a la vez esos hogares en presencia o ausencia. De igual modo, posibilita examinar los casos con al menos alguna actividad migratoria y caracterizar su perfil sociodemográfico, lo que aporta elementos sustanciales sobre la conjunción de diferentes formas de participación en los procesos migratorios. Por último, facilita indagar la incidencia del retorno y vincularla con otras dimensiones del proceso migratorio (remesas y emigración, en particular).

No obstante, este método excluye una dimensión relevante del retorno que no suele medirse de forma empírica y sólo se remite al ámbito de teorizaciones y construcción de hipótesis y conjeturas: la manera en que el proceso de retorno se asume en cada hogar; es decir, si abarca retornos de individuos o si se trata de retornos colectivos, y por tanto, de retornos familiares o al menos de más de un miembro del hogar.

Se ha comentado ampliamente si el retorno sigue una u otra modalidad (individual versus colectiva). El problema radica en que por lo común la forma de medir el retorno en censos, conteos y encuestas, no permite dimensionar directamente el proceso de retorno colectivo, y menos en el caso de hogares que reciben de modo simultáneo migrantes de retorno e inmigrantes internacionales. En censos y encuestas se define el retorno como el regreso de nacionales mexicanos al país, por lo que no se incluye a cónyuges, hijos y descendientes que hayan nacido en Estados Unidos; estos últimos son registrados como inmigrantes internacionales, es decir, personas nacidas en el extranjero que han arribado a México en los últimos cinco años.

Esta situación adquiere particular relevancia, en especial si se considera que la emigración mexicana se conforma preferentemente por personas jóvenes en plenas edades reproductivas. De ahí que sea alta la proporción de migrantes mexicanos casados o con hijos nacidos en Estados Unidos; en varios casos, su retorno pudiera implicar el regreso de sus hijos, cónyuges y otros miembros del hogar no nacionales mexicanos, los cuales no son captados ni registrados como migrantes de retorno en censos y encuestas, sino como inmigrantes internacionales.

En un afán por realizar aportaciones significativas a dicha discusión, proponemos una forma de medición que entraña sesgos, pero que brinda elementos 
empíricos para enriquecer el análisis y la comprensión del fenómeno. Así, estudiamos la composición de los hogares con migrantes de retorno de acuerdo con tres categorías: a) hogares con un migrante de retorno y sin inmigrantes de Estados Unidos, $b$ ) hogares con más de un migrante de retorno y sin inmigrantes de Estados Unidos, c) hogares con uno o más migrantes de retorno y uno o más inmigrantes nacidos en Estados Unidos (inmigrantes internacionales).

Según estas categorías la composición de los hogares posibilita la aproximación a un aspecto difícil de medir y que por esa razón ha sido objeto de análisis hipotético, o bien de estudios de casos que no admiten tener una idea de su dimensión y magnitud estadística. En ese sentido, nuestra categorización trasciende lo propuesto por Gandini, Lozano y Gaspar (2014), porque mide y dimensiona la configuración colectiva/familiar versus individual que puede asumir el proceso de retorno, así como la presencia de otros inmigrantes internacionales no mexicanos junto con migrantes de retorno en un mismo hogar.

La primera categoría refiere un proceso de retorno individual que pareciera no involucrar a otros miembros de la familia. Son hogares en los que en los últimos cinco años antes del levantamiento censal o de la encuesta, sólo ha regresado un migrante mexicano desde Estados Unidos y no han recibido inmigrantes internacionales. La segunda alude a un proceso de retorno colectivo que puede ser familiar. Comprende hogares en los cuales en los últimos cinco años se registra el regreso de más de uno de sus miembros, pero no tiene inmigrantes internacionales. El que los migrantes de retorno compartan un mismo hogar indica que pudiera tratarse de un regreso familiar.

Finalmente, la tercera categoría describe una forma de retorno colectivo en la que regresa más de un miembro del hogar cuya nacionalidad puede ser mexicana o estadounidense. Esta binacionalidad del retorno supone que son procesos de retorno familiar en los que los migrantes regresan con alguno de sus hijos o descendientes nacidos en Estados Unidos, o bien su cónyuge o alguna otra persona nacida en ese país y vinculada a su hogar.

Resulta de particular importancia la tercera categoría porque identifica aquellos hogares con presencia de inmigrantes internacionales cuya movilidad a México se relaciona directamente con el proceso de retorno de algún migrante mexicano, de manera que se asume como parte del fenómeno del retorno, aun cuando en estricto sentido no sean migrantes mexicanos de retorno. En todo caso, no son mexicanos, sino extranjeros. Por ejemplo, cónyuges e hijos de migrantes que nacieron en el extranjero, migran a México y forman parte del 
proceso de retorno. Sin duda, esta categoría no mide a los inmigrantes internacionales que pudieran hallarse en esa condición, pero constituye un acercamiento más certero desde el cual es posible analizar sus perfiles y características fundamentales. ${ }^{9}$

Los datos indican que en los hogares el retorno como proceso colectivo o familiar no es preponderante y que tiende a reducirse en el tiempo. En el quinquenio 1995-2000 el retorno era individual y no acompañado por más de un miembro del hogar en 70 por ciento de los hogares; 17 por ciento correspondía a retornos acompañados y en 13 por ciento de los hogares se daba la combinación de al menos un migrante de retorno con un inmigrante internacional. El predominio del retorno individual se acrecienta con el tiempo, de forma que 79 por ciento de los hogares presentaban este tipo de retorno en el quinquenio 20102015, contra 9 por ciento que registraba retornos acompañados y 12 por ciento con retorno combinado con inmigrante internacional.

\section{CUADRO 2}

Hogares y migrantes según movilidad de retorno

Volumen

\begin{tabular}{lllll}
$1995-2000$ & $2005-2010$ & $2010-2015$ & $1995-2000$ & $2005-$ \\
2010 & $2010-2015$ \\
\hline
\end{tabular}
Distribución relativa

139

\begin{tabular}{|c|c|c|c|c|c|c|}
\hline \multicolumn{7}{|c|}{ Hogares según modalidad de retorno } \\
\hline Total hogares & 191524 & 628460 & 363270 & 100 & 100 & 100 \\
\hline Retorno individual & 134595 & 464746 & 286520 & 70.3 & 73.9 & 78.9 \\
\hline $\begin{array}{r}\text { Retorno } \\
\text { acompañado } \\
\text { nacional }{ }^{*}\end{array}$ & 32629 & 90920 & 34342 & 17.0 & 14.5 & 9.5 \\
\hline $\begin{array}{r}\text { Retorno } \\
\text { acompañado } \\
\text { binacional }^{* *}\end{array}$ & 24300 & 72794 & 42408 & 12.7 & 11.6 & 11.7 \\
\hline \multicolumn{7}{|c|}{ Migrantes según modalidad de retorno } \\
\hline Total migrantes & 302468 & 933335 & 510312 & 100 & 100 & 100 \\
\hline Retorno individual & 134595 & 464746 & 286520 & 44.5 & 49.8 & 56.1 \\
\hline
\end{tabular}

${ }^{9}$ La identificación y cuantificación de estos inmigrantes internacionales asociados al retorno, hará factible depurar la medida que las encuestas y censos arrojan sobre la inmigración internacional, descomponiéndola entre aquellos inmigrantes propiamente tales, de aquellos que forman parte de la migración de retorno. Más adelante ofrecemos algunas cifras al respecto. 
Volumen

$1995-2000$

Retorno

acompañado

nacional"

Retorno

acompañado

binacional"**

* Retorno individual: un migrante mexicano de retorno en el hogar.

** Retorno acompañado nacional: dos o más migrantes mexicanos de retorno en el hogar.

*** Retorno acompañado binacional: uno o más migrantes de retorno mexicanos,

y uno o más inmigrantes internacionales nacidos en Estados Unidos.

Fuente: elaboración propia con datos del Censo de Población (2000, 2010) y Encuesta Intercensal (2015).

En cuanto a la población migrante involucrada en el proceso de retorno, los niveles relativos cambian significativamente pese a que se mantiene el mismo patrón tendencial de preeminencia del retorno no acompañado. En el quinquenio 1995-2000 sólo 44 por ciento de los migrantes involucrados en el retorno regresaban en forma individual, mientras que 56 por ciento lo hacía en forma acompañada; se repartió en proporciones casi iguales entre quienes regresaban acompañados por migrantes de retorno y quienes volvían además con algún migrante nacido en Estados Unidos. En este último caso, puede suponerse que se trata del retorno de un migrante mexicano con algún hijo o descendiente nacido en ese país.

Sin embargo, tal proporción tiende a modificarse en el tiempo. El principal cambio se da en el descenso de los retornos acompañados de sólo mexicanos y en el incremento de los retornos no acompañados; mientras que el retorno que combina arreglos binacionales se mantiene estable en su peso relativo. En concreto, en el quinquenio 2010-2015 los retornos individuales prevalecen al abarcar 56 por ciento de los migrantes involucrados en dicho proceso. En contraste, los retornos acompañados se reducen a sólo 16 por ciento del total, por lo que se convierten en una situación minoritaria. Por último, los retornos acompañados de migrantes nacidos en Estados Unidos se mantienen en 28 por ciento, lo que indica su estabilidad y persistencia en el tiempo, más allá de los avatares de las crisis económicas y las circunstancias migratorias en Estados Unidos.

Ahora bien, como corolario de estas estimaciones, hay un dato novedoso y relevante que hasta ahora se encontraba en el ámbito de las especulaciones y las 
conjeturas: la composición de los inmigrantes internacionales según su vinculación con el proceso de retorno. Es preciso identificar y dimensionar cuántos se asocian al proceso de retorno de mexicanos y cuántos corresponderían a inmigrantes internacionales propiamente tales.

De acuerdo con la definición usada por censos y encuestas mexicanos, inmigrante internacional es la persona nacida en el extranjero que ha inmigrado a México en el quinquenio anterior al levantamiento de la información. No obstante, dicha forma de medir incluye dos componentes muy diferentes entre sí: la inmigración internacional a México y las personas que, aunque nacieron en Estados Unidos, están vinculadas y forman parte de un hogar donde hay algún mexicano de retorno en el mismo periodo quinquenal correspondiente.

La segunda categoría de inmigrante internacional se compone de personas extranjeras relacionadas familiarmente con algún migrante mexicano de retorno (hijos que nacieron en Estados Unidos, cónyuge u otra persona con un vínculo que le permite integrarse a su hogar). Entonces, a esta categoría la denominamos inmigrantes de retorno para distinguirla de los migrantes de retorno, que corresponde a mexicanos que regresan al país, y del concepto tradicional de inmigrante internacional. En estricto sentido no son migrantes de retorno, pues no están volviendo, sino que están inmigrando al país. A diferencia de otros, su particular proceso de inmigración se relaciona directamente con el retorno de algún mexicano miembro de su hogar.

Cabe resaltar que la desagregación de los datos en las dos categorías muestra una situación muy particular. En la estimación global de la inmigración internacional parece dominar la categoría de inmigrantes de retorno sobre la de inmigrantes internacionales. En el quinquenio 1995-2000, por ejemplo, 55 por ciento del total de los extranjeros que residió en el país en realidad correspondía a personas que formaban parte del proceso de retorno de algún mexicano y que por tanto estarían en la categoría de inmigrantes de retorno. En el quinquenio de la crisis, 2005-2010, esta inmigración cobra relevancia con 71 por ciento del total de inmigrantes extranjeros. Se reduce en el quinquenio siguiente a 61 por ciento, proporción que se mantiene por encima del nivel que prevalecía antes de la crisis económica. 
CUADRO 3

Inmigrantes internacionales según modalidad migratoria en México

\begin{tabular}{r|ccc|ccc} 
& & Volumen & \multicolumn{3}{c}{ Distribución relativa } \\
& $1995-2000$ & $2005-2010$ & $2010-2015$ & $1995-2000$ & $2005-2010$ & 2010-2015 \\
\hline $\begin{array}{c}\text { Total inmigrantes } \\
\text { internacionales }\end{array}$ & 64444 & 152593 & 110966 & 100 & 100 & 100 \\
\hdashline $\begin{array}{r}\text { Inmigrantes } \\
\text { de retorno }\end{array}$ & 35318 & 107726 & 67809 & 55 & 71 & 61 \\
$\begin{array}{r}\text { Otros inmigrantes } \\
\text { internacionales }\end{array}$ & 29126 & 44867 & 43157 & 45 & 29 & 39 \\
\hline
\end{tabular}

Fuente: elaboración propia con datos del Censo de Población (2000, 2010) y Encuesta Intercensal (2015).

La implicancia del dato calculado es doble. Por un lado, advierte que desde siempre se ha sobrestimado el volumen de la inmigración internacional. Lo que usualmente se mide como inmigrantes internacionales corresponde en su mayoría (por encima de 55 por ciento) a personas vinculadas directamente con migrantes mexicanos, en particular con migrantes de retorno. A ello cabría agregar a otros inmigrantes que no se asocian con el retorno, pero sí con la emigración o la percepción de remesas; en consecuencia, el volumen de inmigrantes internacionales se reduciría aún más.

Por otro lado, tales estimaciones revelan que también se ha subestimado la migración de retorno al sólo considerar a los migrantes mexicanos que vuelven a su comunidad y al excluir a aquellos extranjeros que regresan con él y que forman parte de su hogar. En esa categoría se incluye a hijos y descendientes de mexicanos nacidos en Estados Unidos, cónyuges y otros inmigrantes nacidos en el extranjero y vinculados al hogar del migrante de retorno. En concreto, en el quinquenio 2005-2010, los inmigrantes de retorno ascendieron a más de $100 \mathrm{mil}$ personas, lo que representa 13 por ciento del total registrado en el censo de 2010 para ese quinquenio, proporción que se eleva a 15 por ciento en el quinquenio siguiente, 2010-2015. Lo anterior constituye una primera aproximación de la subestimación acerca de la migración de retorno y de la sobrestimación de la inmigración internacional al examinar los datos directos de censos y encuestas. Con base en esos datos es posible plantear varias hipótesis en cuanto a la composición y dinámica del proceso de retorno, así como de la estructura de las poblaciones involucradas. 
1. Tiende a ser un proceso de carácter esencialmente individual. El retorno colectivo o acompañado (de más de un migrante por hogar) es menor y se ha reducido aún más en los últimos años.

2. Aunque en los hogares el retorno acompañado no parece ser un fenómeno relevante, sí lo es cuando se analiza la composición de la población involucrada. Al respecto, incluso si la tendencia es a la baja, el retorno acompañado mantiene relevancia porque involucra a 34 por ciento del total de la población que participa directamente en el proceso, esto es, son migrantes de retorno o son inmigrantes internacionales que acompañan a algún migrante de retorno.

3. El retorno de hijos o descendientes junto a sus padres, familiares o algún otro miembro de su hogar es un fenómeno poco significativo a escala de los hogares, pero no marginal en relación con la población involucrada. Si bien sólo en 12 por ciento de los hogares que participan de algún modo del retorno se da la presencia de inmigrantes nacidos en Estados Unidos que acompañan a algún migrante mexicano de retorno, este tipo de retorno acompañado representa a 28 por ciento de la población involucrada.

4. Este tipo de retorno acompañado muestra una gran estabilidad y recurrencia más allá de las circunstancias y coyunturas económicas y políticas. No involucra grandes volúmenes, pero es un fenómeno persistente y estructural que ha sido relegado en los estudios y análisis de las migraciones en general y del retorno en particular.

5. La información obtenida constituye una adecuada estimación de la distorsión en la forma de medir la inmigración internacional. En México, esta forma de medir significa una importante sobrestimación porque incluye a quienes en realidad son parte de algún proceso de retorno migratorio.

\section{Configuración territorial y regional de la migración de retorno}

La migración de retorno es un fenómeno esencialmente rural. Más de 40 por ciento de los migrantes que ha vuelto lo ha hecho hacia localidades rurales o pueblos cuya población es menor a 15 mil habitantes. Sin duda, esto se asocia a que la emigración a Estados Unidos es también un fenómeno rural, como ya lo han demostrado diversos autores. Lo relevante en este contexto es que con la crisis económica y las restricciones migratorias en ese país el retorno ha intensificado 
su carácter rural: 42 por ciento de los retornados residía en localidades rurales y pueblos en el quinquenio 1995-2000; entre 2005-2010, periodo de la crisis económica, la cifra se elevó a 47 por ciento y regresó a su nivel en el periodo de poscrisis.

Asimismo, destaca la muy baja participación de las grandes ciudades y metrópolis Ciudad de México, Guadalajara, Monterrey y Puebla en el fenómeno del retorno y en el proceso migratorio en general, situación que se acentúa durante el periodo de la crisis económica. ${ }^{10}$ En efecto, antes y después de la crisis sólo 15 por ciento de los retornados se dirigió a estas cuatro grandes ciudades, proporción que se redujo a 11 por ciento durante el periodo de la crisis económica y de mayor endurecimiento de la política de deportaciones (quinquenio 2005-2010).

Algo semejante ocurrió en las otras zonas metropolitanas, pero con menor intensidad. Antes y después de la crisis recibían 20 y 21 por ciento de los migrantes de retorno, cantidad que disminuyó a 18 por ciento durante la crisis, a pesar del gran incremento del retorno en ese quinquenio. Finalmente, en las ciudades medias se mantuvo estable al concentrar 23 por ciento de la migración de retorno, tanto antes, durante y después de la crisis económica. La diferencia en cuanto al destino del retorno se ilustra con mayor claridad al analizar las tasas de retorno, esto es, lo que el retorno representa para la población total en cada tipo de localidad.

Es preciso comentar que los datos son igualmente elocuentes: hay un fenómeno de tipo estructural que indica que la tasa de retorno tiende a reducirse según aumenta el tamaño y la importancia de las localidades. Además, dicha diferencia se acentúa y consolida durante la crisis y la poscrisis. Pese a que en el quinquenio 1995-2000 la tasa de retorno en las cuatro metrópolis mencionadas es significativamente menor al resto de las localidades, las distinciones entre las demás no son tan marcadas, a tal punto que el retorno a pueblos y localidades rurales casi tendría el mismo peso relativo que el retorno a ciudades medias. Sólo las zonas metropolitanas regionales exhiben una tasa de retorno un poco inferior, aunque muy superior a la de las cuatro metrópolis.

Durante la crisis económica, sin embargo, las diferencias se realzan y emerge el patrón ya observado. La tasa de retorno en las localidades rurales y pueblos se incrementa en más de tres veces, al pasar de 3.5 por cada mil habitantes en el

${ }^{10}$ En el quinquenio 2005-2010, sólo 13 por ciento de los emigrantes provenía de las zonas metropolitanas de Ciudad de México, Guadalajara, Monterrey y Puebla, las cuatro concentraciones demográficas más grandes del país. Por el contrario, 39 por ciento de los emigrantes a Estados Unidos provenía de localidades rurales (menos de 2.5 mil habitantes). Cálculos propios con base en Censo, 2010. 
quinquenio 1995-2000, a 11.3 por cada mil habitantes en el quinquenio 2005-2010. También se eleva de manera notable la tasa de retorno en las ciudades medias: de 3.4 a 8.6 por cada mil habitantes en los mismos periodos. Lo fundamental es que el aumento de la migración de retorno en las cuatro metrópolis y las zonas metropolitanas regionales es proporcionalmente menor. En el quinquenio de poscrisis 2010-2015 se reducen las tasas de retorno en todas las localidades, se consolida el patrón señalado; es decir, la migración de retorno tiende a ser más importante en las localidades rurales y pueblos pequeños, y disminuye su peso relativo en las ciudades medias, en especial en las cuatro metrópolis.

\section{GRÁFICA 4}

Migración de retorno según tipo y tamaño de la localidad en México

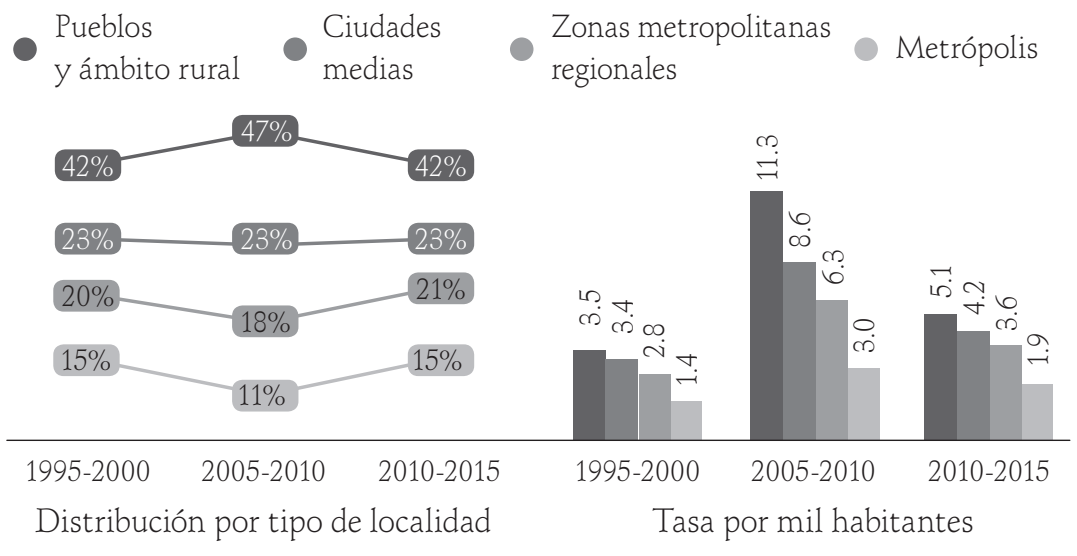

Pueblos y ámbito rural: localidades con menos de 15 mil habitantes.

Ciudades medias: localidades con más de 15 mil habitantes que no forman zonas metropolitanas.

Zonas metropolitanas regionales: con más de 100 mil habitantes, no son metrópolis.

Metrópolis: zonas metropolitanas del Valle de México, Guadalajara, Monterrey, Puebla-Tlaxcala. Fuente: elaboración propia con datos del Censo de Población (2000, 2010) y Encuesta Intercensal (2015).

La composición del retorno por regiones brinda más elementos para una mejor comprensión del fenómeno del retorno en México. Desde nuestra perspectiva, las tendencias y los patrones regionales del retorno expresan la combinación de dos factores: 1. La emergencia de nuevas regiones de emigración que supone la aparición de nuevas regiones de retorno. 2. Las diferentes opciones y recursos de los migrantes frente a la política de deportaciones y la crisis económica en Estados Unidos, en particular del grado de consolidación de redes sociales y familiares 
vinculadas a la migración que actúan como capitales sociales y culturales; es decir, recursos de los migrantes para enfrentar diversas situaciones de riesgo y vulnerabilidad derivadas de procesos estructurales (crisis económica), políticos y sociales (políticas antiinmigrantes, deportaciones masivas, entre otros).

Antes de la crisis el retorno se concentraba en la región de alta tradición migratoria, en entidades del occidente de México. En conjunto, a esas entidades se dirigía 47 por ciento del retorno. Con probabilidad ello se explica por el patrón regional de emigración, según el cual y hasta los 1990 esta región concentraba más de 45 por ciento de la emigración a Estados Unidos. Asimismo, las regiones Frontera Norte y Centro concentraban 25 y 18 por ciento de la migración de retorno, cifras proporcionales a su participación en el proceso. Por último, la región Sur-Sureste apenas recibía 9 por ciento del retorno, concordante con su muy baja participación en el flujo migratorio. Con excepción de las entidades de Oaxaca y - en menor medida - Guerrero, las demás de esa zona tenían un papel marginal en la emigración a Estados Unidos hasta mediados de los 1990. No obstante, en el quinquenio 2005-2010 sucedió un cambio sustancial en el patrón regional del retorno, el cual puede ser consecuencia de los efectos combinados de la emergencia de nuevas regiones migratorias, con impactos diferenciados de la crisis y las deportaciones en los migrantes según su origen regional.

Concerniente a la región tradicional, su participación se reduce a 38 por ciento, 9 puntos porcentuales menos que diez años antes. Ello refleja, por un lado, una disminución regional en la emigración a escala nacional, resultado de la incorporación de nuevas entidades y regiones al proceso migratorio, en particular de la región Sur-Sureste. Por otro lado, su mayor historia migratoria entraña la presencia de redes sociales y familiares más consolidadas, lo que permitiría enfrentar en mejores condiciones los efectos de la crisis económica y de la política antiinmigrante. Mientras tanto, este hecho hace más probable que una mayor proporción de migrantes haya regularizado su situación y estancia legal en Estados Unidos, por lo que logró sortear con mejor fortuna la política de deportaciones y otras medidas restrictivas contra la inmigración.

Frente al descenso relativo de la región con mayor tradición migratoria, surge la región Sur-Sureste, que duplica su participación relativa en el flujo de retorno debido a las mismas razones que en el caso previo, pero en sentido inverso. Ha sido documentada con amplitud la creciente emigración de mexicanos provenientes de dicha región, lo que la ha consolidado como una zona emergente en el proceso migratorio. Por tal motivo, las redes sociales y familiares aún no se 
han fortalecido como en la región tradicional, lo que plantea mayor vulnerabilidad de los migrantes frente a los riesgos de la crisis económica y las deportaciones y políticas restrictivas en Estados Unidos.

La región Centro también ostenta un aumento en su participación relativa en la migración de retorno de 4 puntos porcentuales. Asimismo, las entidades del Norte y de la Frontera Norte presentan pequeñas variaciones, con una leve reducción que no altera en lo fundamental su proceso de retorno. En el quinquenio más reciente, y que da cuenta de la situación posterior a la crisis económica y de la disminución de las deportaciones, la estructura regional del retorno es prácticamente la misma. Se reduce ligeramente el peso de la región de mayor tradición migratoria y se mantiene el peso relativo de las demás.

\section{GRÁFICA 5}

Migración de retorno según región migratoria en México

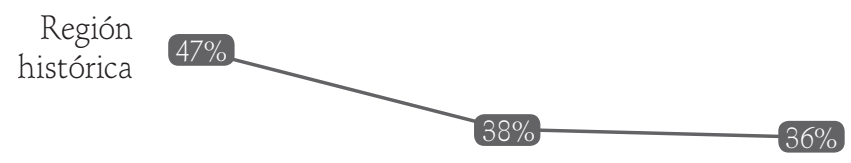

Región histórica

Frontera Norte
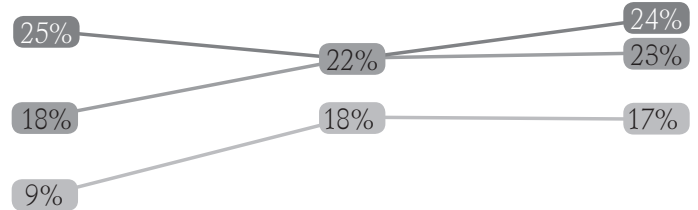

1995-2000 2005-2010-2015

Región histórica: Aguascalientes, Colima, Durango, Guanajuato, Jalisco, Michoacán, Nayarit, San Luis Potosí y Zacatecas.

Región Frontera Norte: Baja California, Baja California Sur, Coahuila, Nuevo León, Sinaloa, Sonora y Tamaulipas.

Región Centro: Ciudad de México, Hidalgo, Estado de México, Morelos, Puebla, Querétaro y Tlaxcala.

Región Sur-Sureste: Campeche, Chiapas, Guerrero, Oaxaca, Quintana Roo, Tabasco, Veracruz y Yucatán.

Fuente: elaboración propia con datos del Censo de Población $(2000,2010)$ y Encuesta Intercensal (2015).

Un tema presente en los estudios y análisis de la migración de retorno es si los migrantes regresan a sus lugares de origen u optan por establecerse en otras localidades y entidades, donde se les ofrecieran mejores opciones para su reinserción económica y social. Cabe cuestionarse porqué un migrante volvería a su 
lugar de origen cuando las condiciones que en un inicio generaron su emigración no habrían cambiado en lo sustantivo. En no pocos casos los estilos de vida y las experiencias y competencias adquiridas en los lugares de destino (ya sea en el trabajo, la escuela o en la vida cotidiana) no siempre pueden desarrollarse y reproducirse en los lugares y localidades de origen; las zonas urbanas y ciudades mayores cuentan con mayores potencialidades.

Complementariamente, habría que considerar el hecho de que gran parte de los emigrantes procede de localidades rurales y pueblos pequeños, pero que al migrar suele establecerse en ciudades medianas y grandes en Estados Unidos, como Los Ángeles y Chicago. Es probable entonces que los migrantes hayan adquirido y se hayan adaptado a nuevos estilos de vida de corte más urbano y metropolitano, con formas de comportamiento, patrones de consumo, estructuras sociales y familiares muy diferentes a las que prevalecen en sus localidades y pueblos de origen. Frente a ello, es natural que el migrante prefiera regresar a otros espacios que le brinden mejores condiciones para reinsertarse social y productivamente, sin perder los capitales sociales y culturales adquiridos como migrantes.

Por desgracia, las fuentes estadísticas en México (censos y encuestas) no permiten identificar el lugar de origen del migrante de retorno, al menos no más allá de su entidad de nacimiento. Esta información parcial ofrece una posibilidad de análisis para una primera aproximación a la dimensión que asume el proceso. Un dato sobresaliente es que entre 21 y 24 por ciento de los migrantes de retorno se instala en una entidad federativa diferente a la de su nacimiento. Es un fenómeno ya registrado en el quinquenio 1995-2000, con 24 por ciento. La cifra se reduce a 21 por ciento durante la crisis económica, debido quizá al incremento del retorno en localidades rurales y pueblos pequeños. Sin embargo, en la poscrisis se eleva de nuevo a 24 por ciento.

En la actualidad, así como en el pasado, prácticamente 1 de cada 4 migrantes no regresa a su entidad de nacimiento. Sólo durante la crisis económica la relación se redujo por ser una situación coyuntural determinada por circunstancias específicas. De cualquier manera, no se trata de una cifra menor, pues la referencia corresponde a una unidad territorial bastante amplia que no incluye los casos de migrantes que vuelven a su entidad, pero a diferente localidad (migrantes de origen rural que suelen regresar a la cabecera municipal, a una ciudad media o a la capital del estado). 


\section{GRÁFICA 6}

Migrantes de retorno que regresan a una entidad

diferente a la de nacimiento

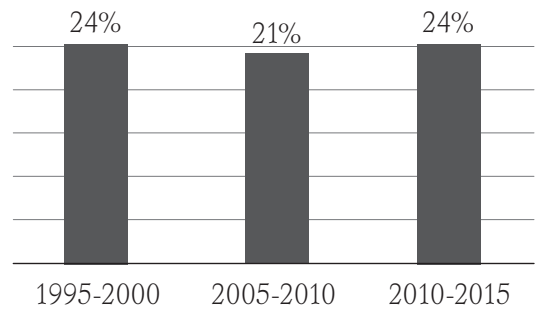

Fuente: elaboración propia con datos del Censo de Población (2000, 2010) y Encuesta Intercensal (2015).

El regreso a entidades distintas a la de nacimiento muestra un patrón muy diferenciado por entidades federativas. En el mapa 1 se identifican las entidades según su capacidad para atraer migrantes de retorno nacidos en otros estados y regiones. En el quinquenio 2010-2015 el indicador fue el porcentaje de migrantes de retorno en cada entidad que no nació ahí. Con base en dicho indicador y considerando que en promedio 25 por ciento de los migrantes regresa a otra entidad, se elaboró una clasificación de cuatro categorías:

1. Entidades con migrantes de retorno nacidos en otras entidades y que constituyen más de 28 por ciento del retorno.

2. Entidades con migrantes externos que representan entre 18 y 28 por ciento (con respecto al promedio nacional).

3. Entidades con migrantes externos que comprenden menos de 18 por ciento del total (muy por debajo del promedio nacional).

4. Entidades en las que el volumen de migrantes de retorno es muy bajo (no permite sustentar el análisis). 
MAPA 1

Entidades según la proporción de migrantes

de retorno nacidos en otras entidades del país, 2010-2015



150 de México, Morelos y Estado de México

18 a 28\%: Chihuahua, Coahuila, Sinaloa, Nayarit, Aguascalientes, Jalisco, Hidalgo

Menos de 18\%: Durango, Zacatecas,

San Luis Potosí, Guanajuato, Michoacán, Guerrero, Puebla, Veracruz, Oaxaca, Chiapas Muy bajo: Baja California Sur, Colima, Querétaro, Tlaxcala, Tabasco, Campeche, Yucatán, Quintana Roo

Fuente: elaboración propia con datos de la Encuesta Intercensal (2015).

Como se observa en el mapa, en la primera categoría con alta atracción de migrantes externos se ubican las entidades de la Frontera Norte, en particular Baja California, donde 69 por ciento de los migrantes de retorno nació en otras entidades. Sin duda es un caso extremo, e ilustra un patrón de retorno en el que los migrantes tienden a permanecer en localidades fronterizas. También resaltan el Estado de México y Morelos, que ostentan una importante capacidad de atraer migrantes de retorno de otros lugares. 
Las entidades con zonas urbanas y metropolitanas de gran dinamismo económico y social ofrecen mayores opciones para los migrantes; aunado a ello la cercanía y vecindad con Estados Unidos en las entidades fronterizas eventualmente puede facilitar una nueva emigración a ese país, a la vez que se conservan los contactos y las relaciones con familiares, amigos y redes sociales desarrollados durante su estancia. En tanto, las entidades del Centro (con excepción de Morelos y Estado de México) experimentan la menor capacidad de atraer migrantes de retorno de otros estados. Son entidades en las que prevalecen mayores niveles de pobreza, marginación y desigualdad social; de ahí que predomine el retorno a localidades rurales y pueblos pequeños. La migración de retorno se conforma principalmente por personas procedentes de esas mismas localidades, pueblos y ciudades pequeñas.

Por último, cuatro entidades del Sur-Sureste (Tabasco, Campeche, Yucatán y Quintana Roo) prácticamente no participan del proceso de retorno. Ello es reflejo de su baja participación en el flujo migratorio. En efecto, poseen las menores tasas de emigración del país y aún no se integran plenamente al flujo migratorio a Estados Unidos. En el quinquenio 2009-2014, la tasa de emigración en dichas entidades no superaba 1.4 migrantes por cada mil habitantes, un tercio de la de otras entidades de la región (Chiapas, Oaxaca, Guerrero y Veracruz) y casi cuatro veces inferior al promedio nacional.

\section{Conclusiones}

La migración de retorno presentó un repentino e inesperado crecimiento como resultado de la crisis económica de la década de los 2000 y la acción de políticas migratorias restrictivas que incluyeron deportaciones masivas. Si bien en los últimos años el volumen de retorno ha sido menor, permanece muy por encima del nivel histórico, lo que demuestra que es un componente del flujo migratorio que adquiere cada vez más importancia y que constituye un elemento sustancial del sistema migratorio México-Estados Unidos. El perfil sociodemográfico del retorno tiende a reproducir e intensificar el perfil sociodemográfico de la emigración. En su mayoría son hombres en edades jóvenes (20 a 39 años) y en menor medida niños y adolescentes, muchos regresan cuando retornan sus padres. En adición, el retorno es más intenso entre los migrantes de menor escolaridad y que provienen de zonas rurales o pueblos pequeños. 
Un aspecto fundamental ya documentado es la composición de los hogares que reciben migrantes de retorno. Los datos indican que en el nivel de los hogares predomina el retorno individual, esto es, no acompañado. Además, en la actualidad, sólo en 12 por ciento de los hogares con migrantes de retorno, éste corresponde a un proceso familiar en el que regresan migrantes nacidos en México y sus hijos y descendientes que han nacido en Estados Unidos. No obstante, al considerar a la población que regresa, los datos desvelan una presencia relativamente notable de migrantes que vuelven en forma acompañada por otros miembros del hogar: 28 por ciento de los migrantes de retorno se compone de mexicanos que regresan acompañados de familiares o descendencia que ha nacido en Estados Unidos. Esta cifra entraña diversos sesgos en su construcción y al mismo tiempo brinda elementos empíricos relveantes sobre un componente del retorno del que se carece de información estadística. Por ahora nos hemos limitado a estimar su volumen y peso relativo, pero es posible profundizar más adelante el análisis a fin de de configurar un perfil social y demográfico de dichos migrantes de retorno y sus hogares.

En cuanto a la configuración territorial del retorno, es un fenómeno esencialmente rural y escasamente metropolitano; asimismo, sigue el perfil del flujo de emigración a Estados Unidos. La región tradicional recibe los mayores volúmenes de retorno. Sin embargo, en términos relativos, el retorno es menor en comparación con su contribución al flujo de salida de migrantes a Estados Unidos. Lo anterior se debe, entre otras cosas, a que su mayor tradición migratoria deriva en una mayor inserción en la sociedad y la economía estadounidenses, con redes sociales y familiares más consolidadas. Todo ello constituye recursos y capitales sociales que les permiten enfrentar con mejor fortuna los avatares de la crisis económica y de la política de deportaciones. Así, el contar ya con varias décadas de migración y asentamiento en Estados Unidos se refleja en mejores opciones y posibilidades para regularizar su situación legal en ese país.

Finalmente, un aspecto que suele comentarse y debatirse respecto al retorno y del que no existe mayor información estadística que respalde análisis y perspectivas se refiere a si los migrantes vuelven a sus localidades y zonas de origen o si optan por retornar a localidades urbanas (ciudades medias y zonas metropolitanas) que les ofrezcan mejores opciones de empleo y condiciones de vida. Los datos apuntan a que 1 de cada 4 migrantes de retorno no vuelve a su entidad de nacimiento. 
Tal circunstancia muestra a su vez grandes diferencias a escala nacional. Mientras algunas entidades, especialmente de la Frontera Norte (Baja California, Sonora, Nuevo León y Tamaulipas), junto a Morelos y el Estado de México, cuentan con gran capacidad para atraer migrantes de retorno de otras entidades, ocurre lo opuesto en las entidades del Centro y Sur-Sureste. Ello sugiere que en cierta medida el retorno se asocia a un proceso de migración interna que sigue los mismos patrones territoriales y regionales de los flujos migratorios interestatales. Es decir, un gran flujo migratorio hacia entidades y ciudades del Norte y de la Frontera Norte, así como hacia el área de influencia de la zona metropolitana del Valle de México. Esto abre otra veta de análisis e investigación concerniente a los eslabones ocultos que vincularían la migración internacional y el retorno con las migraciones internas y los desplazamientos interestatales e interregionales en México.

\section{Referencias}

Alarcón, Rafael (2016), «El régimen de la deportación masiva desde Estados Unidos y los inmigrantes mexicanos», en Alejandro I. Canales (coord.), Debates contemporáneos sobre migración internacional. Una mirada desde América Latina, México, Miguel Ángel Porrúa/Universidad de Guadalajara, pp.161-175.

Alarcón, Rafael y William Becerra (enero-junio 2012), «خ̉Criminales o víctimas? La deportación de migrantes mexicanos de Estados Unidos a Tijuana, Baja California», Norteamérica, 7(1), pp. 125-148, en http://www.redalyc.org/articulo.oa?id= 193724453005

Canales, Alejandro I. (2014), "Crisis económica e inmigración latinoamericana en los Estados Unidos», Revista Latinoamericana de Población, 8(15), pp. 13-34, en http:// www.alapop.org/alap/Revista/Articulos/relap15/relap_15_canales.pdf

Canales, Alejandro I. y Sofía Meza (2016), "Fin del colapso y nuevo escenario migratorio México-Estados Unidos», Migración y Desarrollo, 14(27), pp. 65-107, en http:// www.estudiosdeldesarrollo.mx/revista/rev27/3.pdf

(2018), «El retorno en el nuevo escenario de la migración México-Estados Unidos», en Felipe Aliaga Sáez y Cristhian Uribe Mendoza (eds.), Migración de retorno. Colombia y otros contextos internacionales, Bogotá, Universidad de Santo Tomás, pp. 164-189. 
Canales, Alejandro I. y Martha Luz Rojas (2017), Panorama de la migración internacional en México y Centroamérica. Estudio en el marco del Pacto Global sobre Migraciones. Santiago, Chile, Comisión Económica para América Latina y el Caribe/Organización Internacional para las Migraciones, en https://www.cepal.org/sites/ default/files/events/files/mexico_y_centroamerica_resumen_ejecutivo_revow. pdf

Castles, Stephen y Mark J. Miller (2010), Migration and the global economic crises: one year on, Estados Unidos, Palgrave Macmillan.

Durand, Jorge y Patricia Arias (julio-septiembre, 2014), «Escenarios locales del colapso migratorio. Indicios desde los Altos de Jalisco», Papeles de Población, 20(81), pp. 165-192, en https://rppoblacion.uaemex.mx/article/view/8350

Galindo, Carlos (2015), «Saldo neto migratorio México-Estados Unidos», en Rodolfo Cruz y Félix Acosta (coords.), Migración interna en México. Tendencias recientes en la movilidad interestatal, Tijuana, El Colegio de la Frontera Norte, pp. 217-270.

Gandini, Luciana, Fernando Lozano-Ascencio y Selene Gaspar Olvera (2015), El retorno en el nuevo escenario de la migración entre México y Estados Unidos, Ciudad de México, Consejo Nacional de Población, en https://www.gob.mx/cms/uploads/ attachment/file/39174/ElRetornoEnelNuevoEscenariodeMigracion.pdf (2014), «Migración de retorno y hogares. Un análisis de las transformaciones sociodemográficas y regionales entre 2000 y 2010», La situación demográfica de México, Ciudad de México, Consejo Nacional de Población, pp. 221-243, en http://www. conapo.gob.mx/en/CONAPO/La_Situacion_Demografica_de_Mexico_2014

Gandini, Luciana y Fernando Lozano (2015), "The effects of the crisis on occupational segregation of skilled migrants fron Latin America and the Caribbean in the United States, 2006-2012», Population Space Place, pp. 1-16, en https://doi.org/10 $.1002 /$ psp.1909

(2012), «La migración mexicana calificada en perspectiva comparada: el caso de los profesionistas con posgrado en Estados Unidos, 2001-2010», en Telésforo Ramírez y Manuel Ángel Castillo, El estado de la migración. México ante los recientes desafíos de la migración internacional, Ciudad de México, Consejo Nacional de Población, pp. 83-122, en http://www.conapo.gob.mx/es/CONAPO/E1_Estado_de_la_Migra cion_Mexico_ante_los_recientes_desafios_de_la_migracion_internacional (2015), "Introducción. Las muchas caras del retorno en América Latina», en Fernando Lozano y José Martínez, Retorno de los procesos migratorios de América Latina. Conceptos, debates, evidencias, Río de Janeiro, Asociación Latinoamericana 
de Población, pp. 13-24, en http://www.alapop.org/alap/SerieInvestigaciones/ Si16/AlapSerieInvestigaciones16-book.pdf

Masferrer, Claudia (2014), «De regreso a otro lugar. La relación entre migración interna y la migración de retorno en 2005», en Marcos Valdivia y Fernando Lozano (coords.), Análisis espacial de las remesas, migración de retorno y crecimiento regional en México, Ciudad de México, Universidad Nacional Autónoma de México/Plaza y Valdés, pp. 175-238.

Massey, Douglas, Karen A. Pren y Jorge Durand (2009), «Nuevos escenarios de la migración México-Estados Unidos. Las consecuencias de la guerra antiinmigrante», Papeles de Población (61), pp. 101-128, en https://rppoblacion.uaemex.mx/article/ view/8534

Meissner, Doris, Donald M. Kerwin, Muzaffar Chishti y Claire Bergeron (2013), Immigration enforcement in the United States: the rise of a formidable machinery. Washington DC, Migration Policy Institute, en https://www.migrationpolicy.org/ research/immigration-enforcement-united-states-rise-formidable-machinery

Passel, Jeffrey, D’Vera Cohn y Ana González-Barrera (23 de abril de 2012), «Net migration from Mexico falls to zero and perhaps less», Pew Hispanic Center, en http://www. pewhispanic.org/2012/04/23/net-migration-from-mexico-falls-to-zero-and-perhaps -less/2

Ramírez, Telésforo y Daniel Aguado (2013), «Determinantes de la migración de retorno en México, 2007-2009», La situación demográfica de México, Ciudad de México, Consejo Nacional de Población, pp. 175-190, en http://www.conapo.gob.mx/en/ CONAPO/La_Situacion_Demografica_de_Mexico_2013

Rivera Sánchez, Liliana (2015), «Narrativas de retorno y movilidad. Entre prácticas de involucramiento y espacialidades múltiples en la ciudad», Estudios Políticos (47), pp. 243-264, en http://www.redalyc.org/articulo.oa?id=16440055014

Rodríguez, María (14 de diciembre de 2017), "Qué es el programa Comunidades Seguras que Trump reactivó», ThoughtCo, en https://www.thoughtco.com/que-son-las -comunidades-seguras-1965510 